\title{
Pain reports by older adults in long-term care: A pilot study of changes over time
}

\author{
Margaret C Gibson $\mathrm{PhD}^{1,2}, \mathrm{M}$ Gail Woodbury $\mathrm{PhD}^{1,2}$, Kim Hay RN ${ }^{1}$, Nancy Bol RN MScN ${ }^{1,2}$
}

MC Gibson, MG Woodbury, K Hay, N Bol. Pain reports by older adults in long-term care: A pilot study of changes over time. Pain Res Manage 2005;10(3):159-164.

PURPOSE: To document self-reported pain descriptions throughout residency in a long-term care facility for a convenience sample of older adults (Canadian war veterans).

DESIGN AND METHODS: The present study was a longitudinal, fixed-cohort study with anticipated attrition. Participants $(n=33)$ were assessed every three months from admission until attrition or end of study (three years). The assessments included standardized measures of psychosocial functioning and a comprehensive pain questionnaire for residents who reported a pain problem.

RESULTS: On average, respondents completed five assessments before attrition and reported pain in $69 \%$ of assessments. The likelihood of pain report decreased as the number of assessments increased. Cross-sectional analysis indicated that, at admission, pain duration was greater and nonverbal pain expression less prominent than later in residency. Longitudinal analysis indicated greater than 50\% within-subject variability across three consecutive pain reports for nonpharmacological pain relief, pain expression and functional impact of pain.

CONCLUSION: The present study highlights the need for patientcentred, longitudinal investigations of both the natural progression of pain and environmental factors that mediate pain management in the interests of improving pain control for this population.

Key Words: Longitudinal; Patient-centred; Self-report

\section{Les déclarations de douleur de personnes âgées en soins de longue durée : Un projet pilote des changements au fil du temps}

OBJECTIF : Documenter les descriptions de douleur signalées par les résidents tout au long de leur séjour dans un établissement de soins de longue durée pour obtenir un échantillon de commodité de personnes âgées (anciens combattants canadiens).

CONCEPTION ET MÉTHODOLOGIE : La présente étude était une étude longitudinale de cohortes fixe avec attrition anticipée. Les participants $(\mathrm{n}=33)$ étaient évalués tous les trois mois à compter de l'admission jusqu'à l'attrition ou à la fin de l'étude (trois ans). Les évaluations incluaient des mesures standardisées de fonctionnement psychosocial et un questionnaire complet sur la douleur aux résidents qui déclaraient des problèmes de douleur.

RÉSULTATS : En moyenne, les répondants ont subi cinq évaluations avant l'attrition et ont déclaré des douleurs dans 69 \% d'entre elles. La probabilité de déclaration de douleur était inversement proportionnelle au nombre d'évaluations. Selon l'analyse transversale, à l'admission, la douleur durait plus longtemps et l'expression non verbale de la douleur était moins présente que plus tard pendant le séjour. Dans l'analyse longitudinale, on remarquait plus de $50 \%$ de variabilité chez un même sujet dans trois déclarations de douleur consécutives portant sur un soulagement non pharmacologique de la douleur, l'expression de la douleur et les répercussions fonctionnelles de la douleur.

CONCLUSION : La présente étude souligne le besoin d'explorations longitudinales axées sur les patients, portant à la fois sur la progression naturelle de la douleur et sur les facteurs environnementaux qui assurent la médiation de la prise en charge de la douleur dans l'intérêt d'améliorer le contrôle de la douleur au sein de cette population.
In Canada, 7\% of people aged 65 years or older reside in long-
term care facilities, with the likelihood of institutionalization
increasing from $2 \%$ for those 65 to 74 years of age to $34 \%$ for those
older than 85 years of age (1). American statistics are similar, with
$5 \%$ of adults older than 65 years of age residing in long-term care
facilities at any one time. Approximately $40 \%$ of the elderly pop-
ulation is likely to spend some time in residential care, with the
likelihood of institutionalization increasing with age (2).
Pain prevalence estimates for residents in long-term care
range from $24 \%$ to $83 \%(3,4)$. Estimates vary depending on the
inclusion criteria, assessment tools and measurement
approaches used; however, it is clear that pain is a significant
issue for many older adults in these settings.
Major sources of chronic, nonmalignant pain for long-term
care residents include low back pain, arthritic symptoms, previ-
ous fracture sites and neuropathies (5). Older adults also experi-
ence injuries and require invasive treatment procedures that add
to their burden of pain. Sources of procedure-related pain
include, for example, the placement of nasogastric tubes, central
lines and indwelling catheters (6), and even personal care ( 7 ).
Pain management in long-term care is beginning to receive much needed attention. The American Medical Directors Association has published clinical practice guidelines (8) for pain assessment and management for residents of long-term care facilities. The Joint Commission on Accreditation of Healthcare Organizations in the United States has revised its standards (9) to include a focus on pain in various patient settings, including long-term care. Recent articles have compared pain management practices in long-term care facilities to recommended best practices and have identified opportunities for improvement (10).

There is a need for research to inform and direct intervention efforts specific to this patient population. Significant deficits that have been identified include a lack of self-report data and a lack of longitudinal data in studies of pain presence, intensity and impact on function for older adults $(11,12)$.

\section{Need for self-reported data}

Comprehensive self-reported pain descriptions are essential to enable older adults to be partners in the management of their

\footnotetext{
${ }^{1}$ St Joseph's Health Care London and University of Western Ontario; ${ }^{2}$ Lawson Health Research Institute, London, Ontario

Correspondence and reprints: Dr MC Gibson, Veterans Care Program, Parkwood Hospital, St Joseph's Health Care London,

801 Commissioners Road East, London, Ontario, N6C 5J1. Telephone 519-685-4000, fax 519-685-4031, e-mail Maggie.gibson@sjhc.london.on.ca
} 
own pain (13). That they should be partners rather than passive care recipients is the core assumption of the 'patient-centred care' philosophy of interaction between health care recipients and service providers. The key principles of this philosophy include receptiveness by the care provider to the recipient's opinions and involvement of the care recipient in decisionmaking and treatment planning. A patient-centred perspective forms the basis of quality health service by increasing the likelihood that services are attuned to individual, as well as institutional, needs and agendas (14).

Self-reported pain studies in long-term care generally have been directed toward psychometric issues such as reliability among raters and measures $(15,16)$. The few studies that have focused on obtaining a patient-centred perspective on how pain contributes to the physical, psychological and social aspects of life in residential care are troubling. In one study (17), focus group investigations were conducted with 42 elderly people living in long-term care facilities in Australia. Residents were resigned to having pain, ambivalent about the benefits of taking action to obtain pain relief and reluctant to express that they had pain. An interview study involving 92 long-term care residents in the United States likewise revealed a reluctance to report pain or to bother care providers with pain complaints (5). Survey results for 75 American long-term care residents known to have pain revealed fears regarding addiction and dependence, belief in the immutable nature of persistent pain, and disbelief in the validity of pain complaints without physical deformity or well-defined pathology (18).

It is unknown to what extent environmental characteristics (eg, staffing patterns, activity levels, resident to staff ratios [19] and the attitudes of service providers toward patients with pain [20]) contribute to these perceptions. Similarly, it is unknown whether perceptions differ as a function of an individual's position on the institutional care trajectory (eg, preadmission, short stay and long-term residency) (21). There is an urgent need for self-reported pain description data to develop a patient-centred perspective on improving pain management in the residential care sector of the health care continuum.

\section{Need for longitudinal data}

An understanding of the variability that exists in individual outcomes facilitates interpretation of cross-sectional data, especially for dynamic variables (variables that can be expected to demonstrate change over time) (22). Variability that reflects potentially modifiable lifestyles or environmental factors represents an opportunity for improvement in functional outcomes (23). Studies focused on potentially modifiable environmental factors will provide essential information for improving pain management services in residential care. Longitudinal research, defined as research in which the same persons are observed with respect to the same characteristics for more than two times and during a period long enough to enable ascertainment of changes in these characteristics, is the method of choice for the study of individual variability (24).

Few of the existing large-scale, population-based longitudinal investigations of aging address pain (25). Those that do are limited to a few general questions. Shorter-term, small-scale multipoint studies focused on variability over time for specific issues are needed to supplement the data that can be collected in large, longitudinal datasets (26).

\section{Study objective}

The objective of the present descriptive pilot study was to document self-reported pain quarterly throughout institutional residency for a convenience sample of older adults (Canadian war veterans). The quarterly assessments reflect the standard practice for health assessments with institutionalized populations (27).

\section{The primary research questions were:}

- How do older veterans describe their pain?; and

- How do their pain descriptions change over time?

A secondary research question was: "Does pain reporting vary as a function of reason for study attrition (death versus other)?" Recent reviewers identified the lack of longitudinal studies that cover more than the time period immediately before death as the greatest limitation in end-of-life literature (28). Retrospective research has found that pain increases over the last year of life; however, this finding may be more applicable to the young-old than the old-old (29). Although end-of-life was not the explicit focus of the present study, the longitudinal design permitted a cursory examination of this issue.

\section{Sample}

\section{METHODS}

The participants in the present study were a convenience sample of older adults admitted to the 360-bed Veterans Care Program of a chronic care hospital. Admission to the program was available to eligible veterans from across Canada; however, most new residents were from southwestern Ontario. Approximately one-half of new residents came from acute care facilities, with the remainder split between other long-term care facilities and home. Unlike most chronic care or long-term care populations, most residents were male and veterans of World War II or the Korean War.

The Veterans Care Program included a 110-bed, specialized dementia care service; this group of residents was not included in the study. Study participants were drawn from the inpatient programs for residents with chronic physical illnesses and mental health problems. The most common diagnoses in these programs were chronic obstructive pulmonary disease, depression and general debility.

Over the course of a one-year recruitment period, a member of the treatment team approached new residents about the study $(n=98)$. New residents were approached four to six weeks postadmission to allow them time to settle in. Fifty-seven per cent of residents who were approached $(\mathrm{n}=56)$ were capable of providing informed consent to study participation (ie, they understood the purpose of the study and the implications of participation). Of these, 59\% ( $n=33)$ agreed to be in the study. Those who refused cited disinterest $(n=8)$, poor health $(n=4)$, no time $(n=3)$ or did not provide a reason $(n=8)$. Note that having a pain problem was not a criterion for study eligibility.

\section{Measures}

Standardized Mini-Mental Status Examination (SMMSE): The SMMSE (30) is a standardized (booklet) version of the Mini-Mental Status Examination (31), which has good testretest reliability ( 0.87 to 0.98 ) and concurrent validity ( 0.66 to 0.78). The SMMSE includes 20 questions and yields a score out of 30. SMMSE scores from 24 to 30 are considered normal. Mild, moderate and severe cognitive impairment are indicated by scores in the ranges of 20 to 23,10 to 19 and zero to nine, respectively. 
Geriatric Depression Scale (GDS): The GDS (32) is a 30-item self-report questionnaire used to screen for depression in older adults. It has been validated for use with long-term care residents (33). The psychometric properties include a test-retest reliability of 0.85 at one week and a concurrent validity with other depression self-rating scales of greater than 0.80 (32). A score of 11 to 30 suggests depression.

Anxiety question (ANX): Health-related anxiety was measured by asking, "Do you worry about your health? (Yes/no)". This question was selected through consultation with mental health service providers on the treatment team.

Pain Beliefs Questionnaire (PBQ): The PBQ (34) measures beliefs about pain etiology and control and is applicable to both respondents who have pain and those who are pain-free. Research using a modified version of the scale did not find differences in response patterns as a function of age (35). The PBQ includes 12 items rated on a six-point scale, with higher scores indicating stronger agreement. The PBQ yields two subscale scores, termed Organic Beliefs and Psychological Beliefs (internal reliability 0.73 and 0.70 , respectively; criterion-related validity 0.39 to 0.43 ) (34). The PBQ has not been standardized to compare subscales; therefore, for the purposes of the present study, an individual's endorsement patterns were considered equivalent $(\mathrm{P}=0)$ if scores on the two subscales differed by less than one $\mathrm{SD}$, based on the admission assessment $(\mathrm{SD}=1.33)$.

Delighted-Terrible Quality of Life Scale (QoL): The respondent selects one answer to the question "Which of these best describes how you feel about your life?" from a scale that includes three positive response options (mostly satisfied, pleased and delighted) and four negative response options (mixed, mostly dissatisfied, unhappy and terrible). Validity and test-retest reliability have been reported at 0.82 and 0.70 , respectively (36).

Comprehensive pain assessment: The pain assessment used in the present study was based on the model provided by McCaffery and Beebe (37). Information was solicited through a combination of direct questions, open-ended questions, prompts and response scales to yield a comprehensive description of pain experience for respondents who reported having a pain problem at the time of the assessment. Except for the ratings for present pain intensity, the pain questions were designed to elicit responses that described the 'usual' pain felt by the patients.

Pain reports were summarized according to the following categories:

- Pain type: Information about pain location and etiology (disease or condition reported as the cause of the pain; selfreport was accepted as valid) were used through inferred pathology (37) to categorize pain as:

i) Nociceptive/somatic;

ii) Nociceptive/visceral; and

iii) Neuropathic.

- Pain exposure: Pain was categorized as episodic or constant. Onset of pain was categorized as:

i) Older adulthood (age 60+);

ii) Middle adulthood (age 40-60); and

iii) Youth or early adulthood (age 0-40).

- Pain intensity: A numerical rating scale (zero to 10) was used to rate present, best, worst and acceptable pain intensity. Present pain intensity was also rated using the Present Pain Intensity scale of the McGill Pain Questionnaire (38).
- Pain quality: Responses to the question "What does your pain feel like?" were categorized as:

i) Dull, aching, throbbing or other related term;

ii) Sharp, shooting, burning or other related term; and

iii) Other term (dissimilar to above).

- Pain exacerbation: Responses to the question "What can make your pain worse?" were categorized as:

i) Physical (eg, sudden/excessive movement and prolonged rest);

ii) Cognitive/emotional (eg, stress and anger);

iii) Sensory (eg, touch and pressure); and

iv) Temporal factors (time of day).

- Pain expression: Responses to the questions "How do you show you are in pain?" and "How would others know you are in pain?" were categorized as:

i) Request pain medication;

ii) Expressed through behaviours (eg, rubbing, grimacing, wincing and withdrawal from touch) or nonverbal vocalizations (eg, moaning, groaning and crying); and

iii) Expressed verbally (eg explanations, complaints and pain words such as 'ouch').

- Pain impact: Responses to the question "How does pain affect your day-to-day life?" were categorized as:

i) Physical impact (eg, impairs sleep, appetite, activity level and feel 'sick');

ii) Psychosocial impact (eg, impairs relationships and elicits negative emotions); and

iii) Cognitive impact (eg, impairs concentration).

- Pain relief: Responses were categorized as:

i) Pharmacological (prescribed, over the counter and alternative); and

ii) Nonpharmacological (eg, bed rest, heat/cold application and exercise).

\section{Procedure}

Ethics approval for the present study was obtained from the ethics review board of the affiliated university, and permission to conduct the study was obtained from the hospital research review committee. Informed consent was reaffirmed at each interview, sessions were carefully paced to conserve energy, sensory deficits were taken into consideration, and sufficient time was allotted to ensure that residents experienced the interview as a positive social interaction (39).

Admission interviews were conducted in the second or third month of residency. Subsequent interviews were conducted quarterly (every three months) for 36 months or until the resident was lost to follow-up. At each interview, participants completed the PBQ, GDS, SMMSE, ANX and QoL. Participants who reported having a pain problem also completed the Comprehensive Pain Assessment.

\section{Sample characteristics}

\section{RESULTS}

Thirty-two of the 33 study participants were male. Average age was 77 years $(S D=4.1$, range 66 to 85 years, median $=77$ years). At the admission assessment, mean score on the SMMSE was in the normal range $(27, \mathrm{SD}=4)$, as was the mean GDS score 


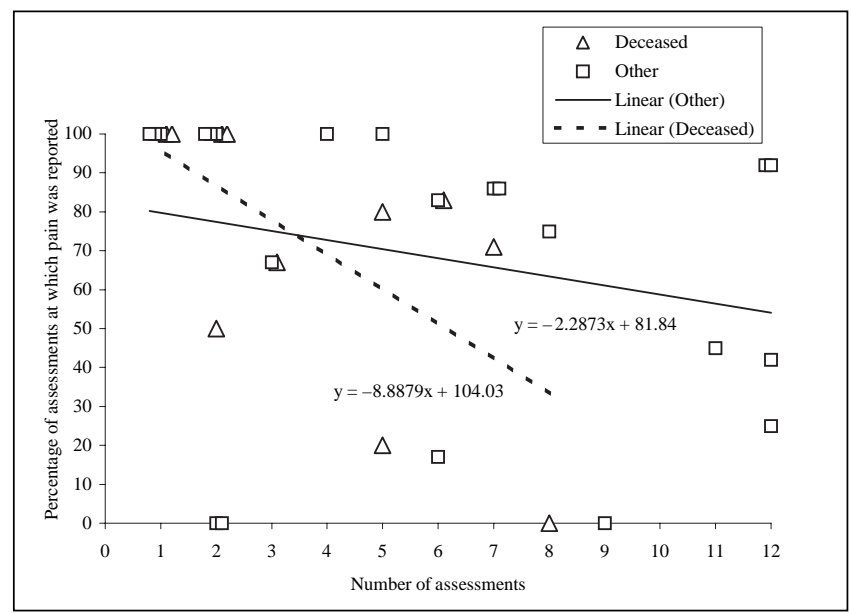

Figure 1) Individual data: Percentage of assessments with pain reports as a function of number of assessments

$(9, \mathrm{SD}=5)$. Fifty-five per cent of respondents indicated that they were worried about their health (ANX), while $46 \%$ rated satisfactory or better on the QoL. Mean ratings on the PBQ did not favour psychological over organic factors to explain pain etiology and control $(\mathrm{P}=0)$.

\section{Attrition}

At the time the study commenced, the average life expectancy postadmission for residents was two years (40). For comparison, the life expectancy at age 65 for Canadian men overall in 2001 was 17.1 additional years (41).

On average, residents participated in five assessments (representing approximately 15 months study enrollment). The study was terminated after three years, when only four participants remained. Death was the most common reason for study attrition $(n=11)$. Causes of death were related to chronic illnesses (heart: $n=3$; renal: $n=2$; pancreas: $n=2$; esophageal disease: $n=1)$, stroke $(n=2)$ and aspiration pneumonia $(n=1)$. Other reasons for study attrition were discharge from the facility $(n=4)$ and withdrawal. Participants elected to withdraw $(n=9)$ or were withdrawn from the study by the interviewer in response to changes in their health status that rendered them unable to provide continuing informed consent or too frail to tolerate the interview process $(n=5)$.

\section{Pain reporting}

Twelve per cent of residents never reported pain. The majority $(88 \%)$ reported pain on at least one assessment. Pain was reported on admission by $60 \%$ of residents, and by $56 \%$ of residents at the final assessment before attrition. A percentage of pain reporting for each individual was calculated by dividing the number of assessments at which each resident reported pain by the total number of assessments that the resident completed. On average, residents reported pain at $69 \%$ of their assessments. The tendency was for the likelihood of pain reporting to decrease as the number of assessments increased $(y=-3.1108 x+85.053)$.

This analysis was repeated as a function of reasons for attrition by comparing deceased $(n=11)$ versus other $(n=22)$ participants (Figure 1). On average, participants who died during the study period completed four assessments, while others completed six assessments. The mean number of assessments at
TABLE 1

Pain characteristics on admission $(n=20)$

\begin{tabular}{llc}
\hline Characteristic & & Per cent \\
\hline Pain type & Nociceptive/somatic & 75 \\
& Nociceptive/visceral & 10 \\
Present pain intensity & Neuropathic & 15 \\
& None & 20 \\
& Mild & 20 \\
& Discomforting & 40 \\
& Distressing & 15 \\
Pain quality & Horrible & 5 \\
& Excruciating & - \\
& Dull/aching & 35 \\
& Sharp/shooting & 30 \\
& Both (dull/aching and sharp/shooting) & 15 \\
& Other/no response & 20 \\
\hline
\end{tabular}

which pain was reported for participants who died was $70 \%$, which was similar to that reported by others (69\%). The slope of the regression line for percentage of assessments at which pain was reported as a function of number of assessments completed did not differ significantly $(\mathrm{P}=0.178)$ for participants who died versus those who did not.

\section{Pain description}

Residents typically described somatic pain conditions originating in older adulthood. "Discomforting" was the attribute most often selected on the Present Pain Intensity scale. Many residents consistently struggled to describe pain quality and ultimately endorsed both categories (dull/aching and sharp/shooting) or declined the question. Results for pain type, intensity and quality for residents who reported pain on the admission assessment $(\mathrm{n}=20)$ are shown in Table 1.

Across assessments, numerical (zero to 10) ratings for present, worst, best and acceptable pain intensity followed a logically consistent pattern (best greater than worst, acceptable slightly above best). Residents most often attributed pain exacerbation to physical factors and time of day, and reported a negative impact of pain on both physical and psychological function. The majority of residents reported use of both pharmacological and nonpharmacological pain relief interventions. Approximately one-half noted that they requested pain medications directly.

The only pain descriptors for which substantive (defined as greater than 30\%) group differences related to length of stay were suggested were pain duration and pain expression. Pain was described as constant by approximately one-half of residents with pain on admission; however, at the last assessment before attrition, the proportion reporting constant pain was less than one-quarter of residents. With respect to pain expression, on admission, approximately one-third of residents reported using nonverbal vocalizations and behaviours to indicate they were in pain. On the final assessment before attrition, this proportion was doubled.

\section{Variability}

Longitudinal descriptions of within-subject variability were examined for participants who had at least three assessments at which pain was reported $(n=14)$. Variability was defined as 
providing different responses (eg, "yes", “no", “yes”) to the same question on different assessments. The pain descriptors that were endorsed by at least $30 \%$ of respondents and for which variability rates were greater than $50 \%$ are presented in Figure 2. Use of behaviours and nonverbal vocalizations to communicate pain, pain verbalizations, impact of pain on physical and psychosocial functioning, and pain relief from nonpharmacological interventions varied substantively over time within subjects.

\section{DISCUSSION}

Pain descriptions were documented throughout residency in an institutional care setting for a convenience sample of older adults (Canadian war veterans). Limitations on generalizability include the small sample size, specificity of the sample (Canadian war veterans, predominantly male and able to give informed consent to research participation) and variable attrition rate (however, this is an expected component of longitudinal research in this population).

Despite these limitations, the present descriptive pilot study represents one of the few self-report, longitudinal pain studies to have been conducted with an institutionalized older adult sample. The findings highlight two main issues that warrant further investigation in the interests of improved pain management in this health care sector.

First, it is notable that pain reporting tended to decline as the number of assessments increased. This trend was observed even in those residents who deceased during the course of the study. Moreover, pain was described as episodic rather than constant more often at later stages of residency. Hopefully, these findings reflect a progressive improvement in pain outcomes over time, even for residents who are palliative. Alternatively, it may be that factors such as learned helplessness account for the decline in pain reporting over time. Further research is needed to disentangle these effects in the interests of service enhancement and quality improvement.

Second, these results highlight the need for more research on environmental factors as mediators of pain control in this setting. Environmental factors include, for example, caregiver responsiveness (42), staff knowledge (43), and the availability and distribution of resources in the institutional care environment (44).

In long-term care facilities, the high prevalence of residents with impaired cognitive function contributes to a heightened responsiveness to behaviour in general (45). If pain behaviours garner more attention than verbal pain communication, this circumstance may contribute to the observed variability in within-subject pain expression, as well as the propensity for behavioural pain expression to increase over time. Benefits, such as quicker access to intervention, may accrue to the resident who uses behavioural strategies for accessing staff attention, but there may also be negative consequences, such as reduced responsiveness to direct communication (46) and promulgation of unsatisfying social interaction patterns (47).

Environmental factors may also be implicated in the substantial variability observed in the self-reported impact of pain on function. Factors that may mediate the impact of pain include exposure to exacerbating stimuli (eg, insufficient assistance with transfers) and availability of support (eg, emotional support for decision-making around treatment goals and care options). Qualitative research is needed to examine the dynamic impact of pain on the developmental, pragmatic,

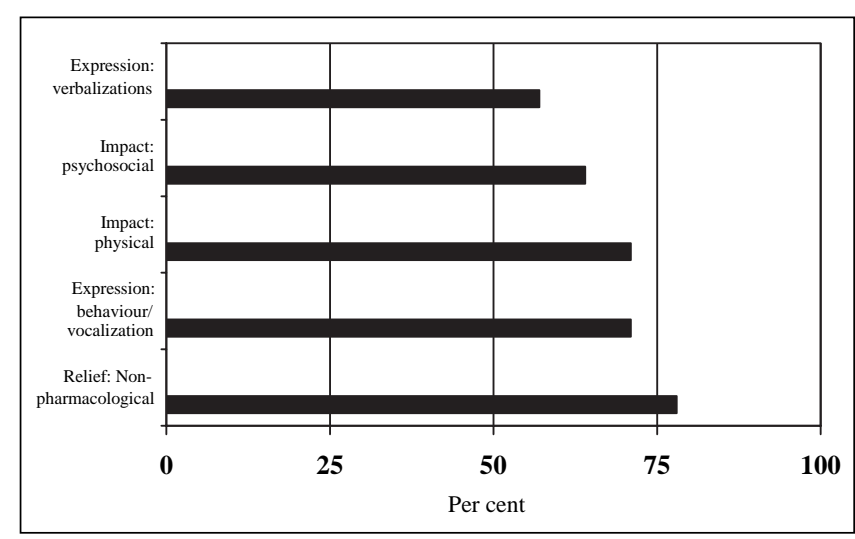

Figure 2) Pain descriptors with greater than 50\% variability across three assessments

existential and interpersonal challenges that older adults in residential care encounter in the course of daily life (48).

Pain relief may also be significantly shaped by environmental factors. Relief from nonpharmacological intervention was variable across consecutive pain assessments for $78 \%$ of respondents. In contrast, pain relief from pharmacological interventions was variable for only $14 \%$ of respondents, with the majority reporting consistent effective relief. Pain relief is contingent on several factors, including effectiveness of the intervention, access to the intervention, and adequacy and timeliness of access (48). Previous research suggests that nonpharmacological interventions are underused in long-term care. A self-report study on the pain assessment and intervention practices of long-term care nurses found that nurses were familiar with basic nonpharmacological pain control interventions, but suggested these interventions to residents in addition to pharmacological strategies only $38 \%$ of the time on average (49).

In summary, the results of the present descriptive pilot study of pain in older adults in a long-term care setting strongly support the need for patient-centred, longitudinal investigations of both the natural progression of pain and environmental factors that mediate pain management in the interest of improving pain control for this population.

ACKNOWLEDGEMENT: This research was supported by a grant from the Parkwood Hospital Foundation, London, Ontario.

\section{REFERENCES}

1. Statistics Canada. A Portrait of Seniors in Canada, 3rd edn. Ottawa: Minister of Industry, 1999. Cat 89-519-XPE.

2. Ferrell BA. Overview of pain and aging. In: Ferrell BR, Ferrell BA, eds. Pain in the Elderly. Seattle: IASP Press, 1996:1-10.

3. Fox PL, Raina P, Jadad AR. Prevalence and treatment of pain in older adults in nursing homes and other long-term care institutions: A systematic review. CMAJ 1999;160:329-33.

4. Proctor WR, Hirdes JP. Pain and cognitive status among nursing home residents in Canada. Pain Res Manage 2001:6:119-25.

5. Ferrell BA, Ferrell BR, Osterweil D. Pain in the nursing home. J Am Geriatr Soc 1990;38:409-14.

6. Morrison RS, Ahronheim JC, Morrison GR, et al. Pain and discomfort associated with common hospital procedures and experiences. J Pain Symptom Manage 1998;15:91-101.

7. Feldt KS, Warne MA, Ryden MB. Examining pain in aggressive cognitively impaired older adults. J Gerontol Nurs 1998;24:14-22.

8. American Medical Directors Association. Chronic Pain Management in the Long-Term Care Setting. Columbia, Maryland: American Medical Directors Association, 1999. 
9. Joint Commission on Accreditation of Healthcare Organizations. Comprehensive Accreditation Manual for Long-Term Care (Dementia and Subacute Included). Oakbrook Terrace, Illinois: Commission on Accreditation of Healthcare Organizations, 2000.

10. Gibson MC, Bol N. Changing practice: Improving pain management for older adults in long-term care. Top Geriatr Rehabil 2001;16:56-65

11. Miller LL, Talerico KA. Pain in older adults. Annu Rev Nurs Res 2002;20:63-88

12. Helme RD, Gibson SJ. Pain in older people. In: Crombie IK, ed. Epidemiology of Pain. Seattle: IASP Press, 1999:103-12.

13. Cowan DT, Fitzpatrick JM, Roberts JD, While AE, Baldwin J. The assessment and management of pain among older people in care homes: Current status and future directions. Int J Nurs Stud 2003;40:291-8.

14. McWilliam CL, Belle Brown J, Carmichael JL, Lehman JM. A new perspective on threatened autonomy in elderly persons: The disempowering process. Soc Sci Med 1994;38:327-38.

15. Cohen-Mansfield J. Relatives' assessment of pain in cognitively impaired nursing home residents. J Pain Symptom Manage 2002;24:562-71.

16. Kamel HK, Phlavan M, Malekgoudarzi B, Gogel P, Morely JE. Utilizing pain assessment scales increases the frequency of diagnosing pain among elderly nursing home residents. J Pain Symptom Manage 2002;21:450-5.

17. Yates P, Dewar A, Fentiman B. Pain: The views of elderly people living in long-term residential care settings. J Adv Nurs 1995;21:667-74.

18. Weiner DK, Rudy TE. Attitudinal barriers to effective treatment of persistent pain in nursing home residents. J Am Geriatr Soc 2002;50:2035-40

19. Shore BA, Lerman DC, Smith RG, Iwata BA, DeLeon IG. Direct assessment of quality of care in a geriatric nursing home. J Appl Behav Anal 1995;28:435-48.

20. Blomqvist K. Older people in persistent pain: Nursing and paramedical staff perceptions and pain management. J Adv Nurs 2003;41:575-84.

21. Mehdizadeh SA. Health and long-term care use trajectories of older disabled women. Gerontologist 2002;42:304-13.

22. Collins LM. Measurement of change in research on aging: Old and new issues from an individual growth perspective. In: Birren JE, Schaie KW, eds. Handbook of the Psychology of Aging. San Diego: University Press, 1996:38-56.

23. Birren JE, Dieckmann LL, Schroots JJF. Prolegomena to the next generation of longitudinal research on health and aging. In: Schroots JJF, ed. Aging, Health and Competence. New York: Elsevier Science Publishers, 1993:357-69.

24. Deeg DJH, Van Der Zanden GH. Experiences from longitudinal studies of aging: An international perspective. J Cross Cult Gerontol 1991;6:7-22.

25. Health Canada. Review of Longitudinal Studies on Aging Working Document. Ottawa: Division of Aging and Seniors, Health Canada, 2002.

26. Havens B. Overview of longitudinal research on aging. Can J Aging 1995;14(Suppl 1):119-34.

27. Brown DL. Long Term Care Facility Resident Assessment Instrument (RAI) User's Manual. Natick, Massachusetts: Eliot Press, 1995.

28. George LK. Research design in end-of-life research: State of science. Gerontologist 2002;42(Spec No 3):86-98.
29. Moss MS, Lawton MP, Glicksman A. The role of pain in the last year of life of older persons. J Gerontol Psychol Sci 1991;46:51-7.

30. Molloy DW, Alemayehu E, Roberts R. Reliability of a Standardized Mini-Mental State Examination compared with the traditional MiniMental State Examination. Am J Psychiatry 1991;148:102-5.

31. Folstein MF, Folstein SE, McHugh PR. "Mini-Mental State". A practical method for grading the cognitive state of patients for the clinician. J Psychiatr Res 1975;12:189-98.

32. Yesavage JA, Brink TL, Rose TL, Leirer VO. Development and validation of a geriatric depression screening scale: A preliminary report. J Psychiatr Res 1983;17:37-49.

33. McGivney SA, Mulvihill M, Taylor B. Validating the GDS depression screen in the nursing home. J Am Geriatr Soc 1994:42:490-2.

34. Edwards LC, Pearce SA, Turner-Stokes L, Jones A. The Pain Beliefs Questionnaire: An investigation of beliefs in the causes and consequences of pain. Pain 1992;51:267-72.

35. Gagliese L, Melzack R. Age differences in the quality of chronic pain A preliminary study. Pain Res Manag 1997;2:157-62

36. McDowell I, Newell C. Measuring Health: A Guide to Rating Scales and Questionnaires, 2nd edn. Oxford: Oxford University Press, 1996

37. McCaffery M, Beebe A. Pain: Clinical Manual, 2nd edn. St Louis: Mosby, 1999.

38. Melzack R. The McGill Pain Questionnaire: Major properties and scoring methods. Pain 1975;1:277-99.

39. Bowsher J, Bramlett M, Burnside IM, Gueldner SH. Methodological considerations in the study of frail elderly people. J Adv Nurs 1993; 18:873-9.

40. Veterans Affairs Canada. Review of Veterans Care Needs Project. Ottawa: Veterans Affairs Canada, 1999.

41. Statistics Canada. (36a-HLT) Life expectancy - abridged life table, at age 65, by sex, Canada, provinces and territories, 2001. $<$ www.statcan.ca/english/freepub/82-401-XIE/2002000/tables/ html/dt005 en.htm> (Version current at March 24, 2005).

42. Hadjistavropoulos T, Craig KD. A theoretical framework for understanding self-report and observational measures of pain: A communications model. Behav Res Ther 2002;40:551-70.

43. Sloman R, Ahern M, Wright A, Brown L. Nurses' knowledge of pain in the elderly. J Pain Symptom Manage 2001;21:317-22.

44. Weissman DE, Matson S. Pain assessment and management in the long-term care setting. Theor Med 1999;20:31-43.

45. Wright J, Varholak D, Costello J. Voices from the margin: The nurse aide's role in pain management of institutionalized elders. Am J Alzheimers Dis Other Demen 2003;18:154-8.

46. Cariaga J, Burgio L, Flynn W, Martin D. A controlled study of disruptive vocalizations among geriatric residents in nursing homes. J Am Geriatr Soc 1991;39:501-7.

47. Matteau E, Landreville P, Laplante L, Laplante C. Disruptive vocalizations: A means to communicate in dementia? Am J Alzheimers Dis Other Demen 2003;18:147-53.

48. Foy SS, Mitchell MM. Factors contributing to learned helplessness in the institutionalized elderly: A literature review. Phys Occup Ther Geriatr 1991;9:1-23.

49. Mrozek JE, Werner JS. Nurses' attitudes toward pain, pain assessment, and pain management practices in long-term care facilities. Pain Manag Nurs 2001;2:154-62. 


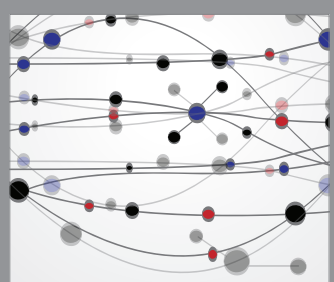

The Scientific World Journal
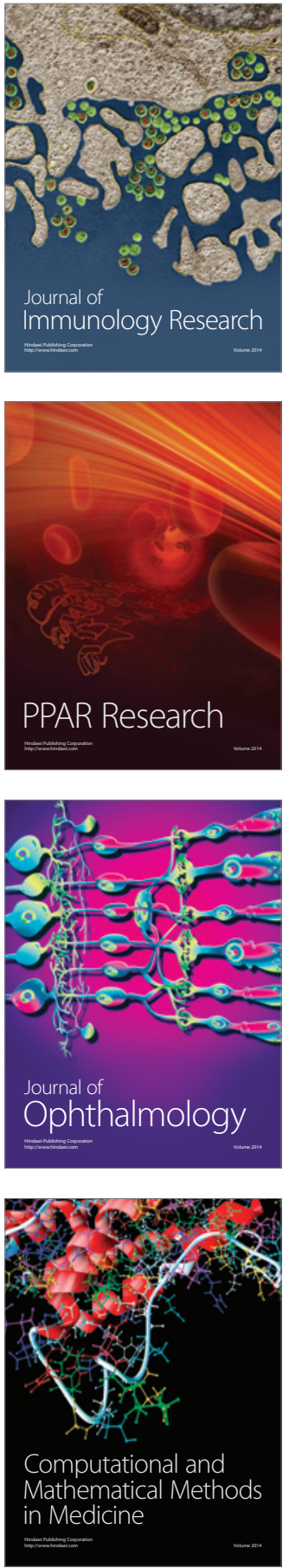

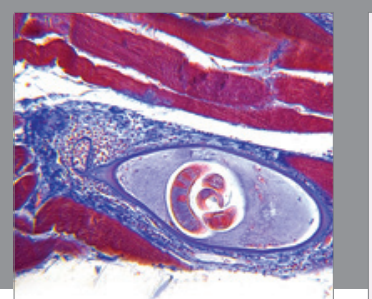

Gastroenterology Research and Practice

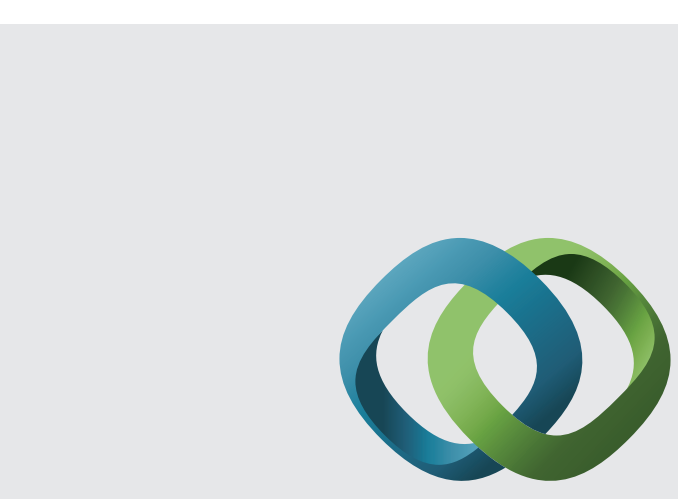

\section{Hindawi}

Submit your manuscripts at

http://www.hindawi.com
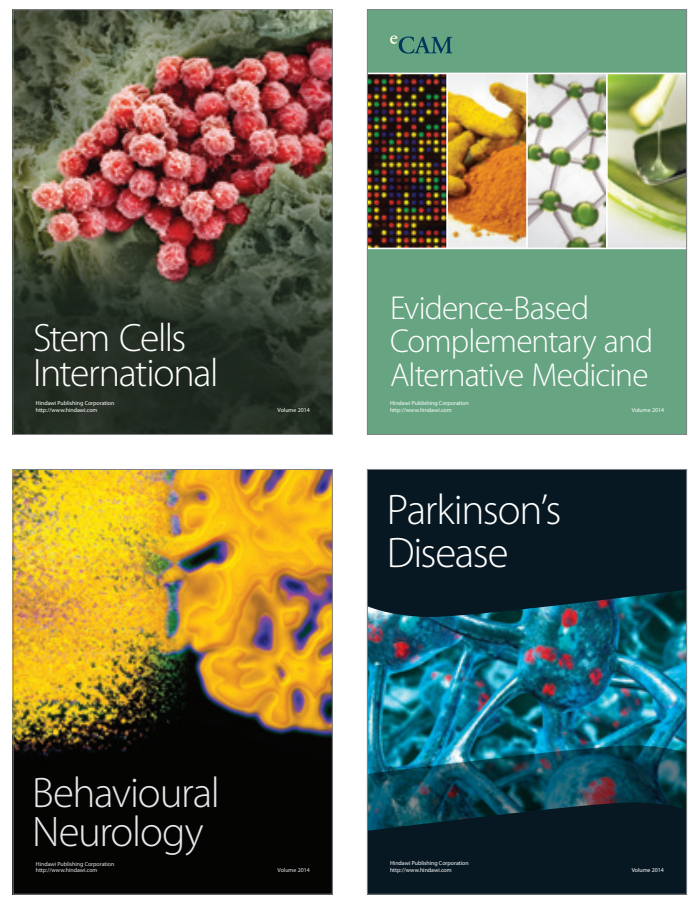
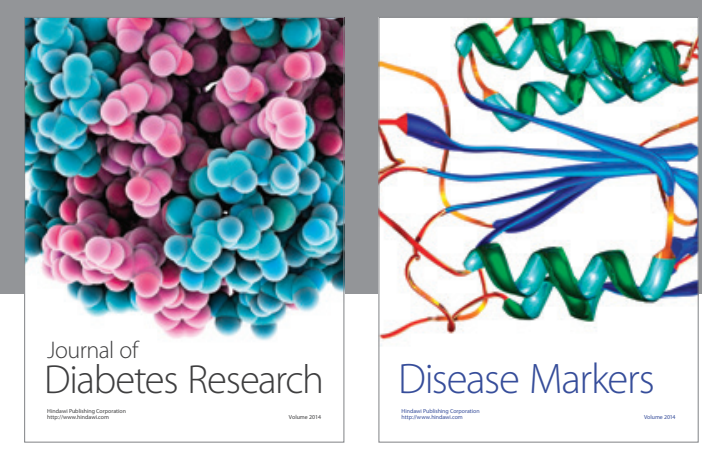

Disease Markers
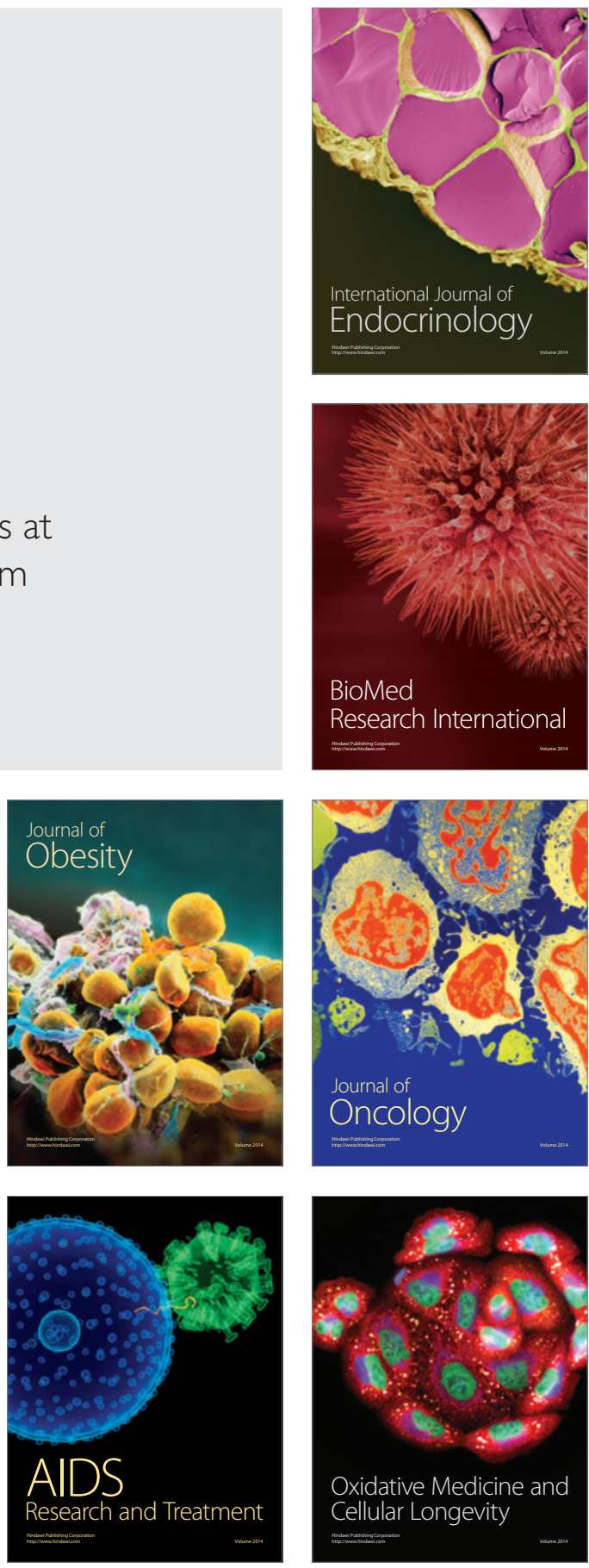